\title{
ARTICLE
}

\section{Palladium-catalysed formation of vicinal all-carbon quaternary centres via propargylation}

Xin Huang ${ }^{1}$, Shangze $\mathrm{Wu}^{1}$, Wangteng $\mathrm{Wu}^{1}$, Pengbin $\mathrm{Li}^{1}$, Chunling $\mathrm{Fu}^{1} \&$ Shengming $\mathrm{Ma}^{1}$

Construction of two vicinal all-carbon quaternary carbon centres is of great importance due to the common presence of such units in natural and unnatural molecules with attractive functions. However, it remains a significant challenge. Here, we have developed a palladiumcatalysed general coupling for the efficient connection of two tertiary carbon atoms: Specifically, propargylic carbonate has been treated with a fully loaded soft functionalized nucleophile to connect such two fully loaded carbon atoms with a simple palladium catalyst. It is observed that the central chirality in the optically active tertiary propargylic carbonates has been remembered and transferred into the products with very high efficiency. The triple bond and the functional groups such as ester, cyano and unsaturated $\mathrm{C}-\mathrm{C}$ bonds make this method a relatively general solution for such a purpose due to their high synthetic versatility.

\footnotetext{
${ }^{1}$ Department of Chemistry, Laboratory of Molecular Recognition and Synthesis, Zhejiang University, Hangzhou, Zhejiang 310027, China. Correspondence and requests for materials should be addressed to S.M. (email: masm@sioc.ac.cn).
} 
C arbon-carbon bond formation is an ever-lasting topic in organic chemistry-related sciences such as synthesis, drug discovery and materials. Of particular interest is a contiguous array of all-carbon quaternary centres, which are found in many complex natural products with remarkable biological activities ${ }^{1-4}$. However, the efficient creation of such entities by carbon-carbon bond formation reaction is still challenging ${ }^{5-7}$. The most direct approach would be the coupling reaction of two related carbon species; however, this is largely underdeveloped due to the extremely strong steric effect and the intrinsic challenge of $\beta-\mathrm{H}$ elimination forming the olefins (equations (1) and (2), Fig. 1a). For a selection of such efforts, see refs $8-11$. So far, the commonly notable approach is the allylic substitution reaction with an issue of regioselectivity, which is obviously still in its early stage in terms of the scope (equation (3), Fig. 1a) ${ }^{12-19}$.

Propargylic carbonates are a class of very common organic compounds with already well-established versatile attractive reactivities in organic synthesis. Since Tsuji's first report in 1985 (ref. 20), palladium-catalysed transformations of propargylic alcohols or their derivatives have become a useful tool for constructing carbon-carbon and carbon-heteroatom bonds. In most cases, these reactions give rise to the corresponding allenyl palladium species $\mathrm{A}$ via different approaches $\left(S_{N} 2^{\prime}\right.$-type oxidative addition plus $S_{N} 2$-type oxidative addition followed by isomerization via intermediate $\mathbf{B}$ ), which was followed by the coupling reaction with a hard carbon nucleophile to form the allene derivatives or by the attack of two molecules of soft carbon nucleophiles to form the corresponding alkene derivatives (Path 1, Fig. 1b) ${ }^{21,22}$. In rare cases, the direct propargylic substitution with simple carbon nucleophiles has been reported as the minor byproducts or major products (Path 2, Fig. 1b) ${ }^{23-27}$; however, to the best of our knowledge, the propargylations of tertiary propargylic alcohol derivatives with fully loaded soft carbon nucleophiles have never been realized. We reasoned that, by applying a suitable ligand together with optimized reaction parameters, the $S_{N} 2^{\prime}$-type oxidative addition would be shut down; with that the $S_{N} 2$-type oxidative addition would give $\eta^{1}$-propargylic palladium $\mathbf{C}$ exclusively with the absolute configuration inverted. If such a ligand makes the palladium in C coordination-saturated, this intermediate would NOT isomerize to $\eta^{1}$-allenylic palladium $\mathbf{A}$ mostly via the intermediacy of $\eta^{3}$-dinuclear palladium intermediate $\mathbf{B}$, as shown by Ogoshi et $a{ }^{28}$. In addition, the intrinsic $\beta-\mathrm{H}$ elimination should also be avoided for the same reason. Finally, the highly reactive propargylic nature may make this intermediate $\mathbf{C}$ reactive enough to undergo reaction with a sterically hindered tertiary carbon nucleophile. If the stereoselectivity may be controlled, an efficient, highly stereoselective connection of two tertiary carbon atoms may be fulfilled. As an extra bonus, the synthetic potential of the $\mathrm{C}-\mathrm{C}$ triple bond is attractive, since it may undergo further deliberate synthetic elaboration for different purposes as

a

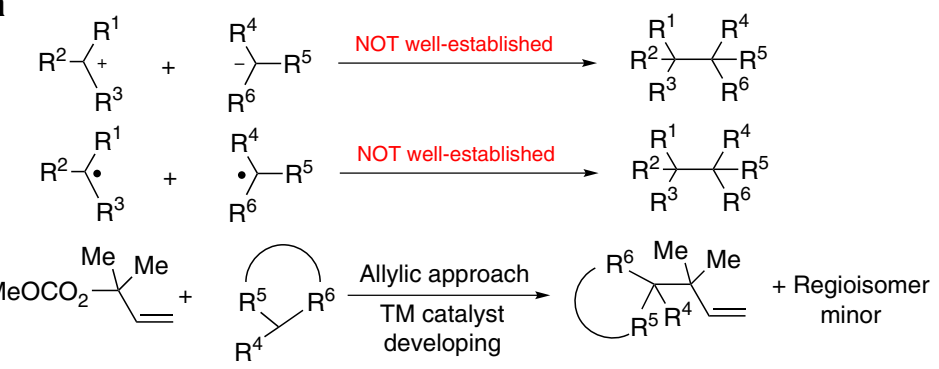

b

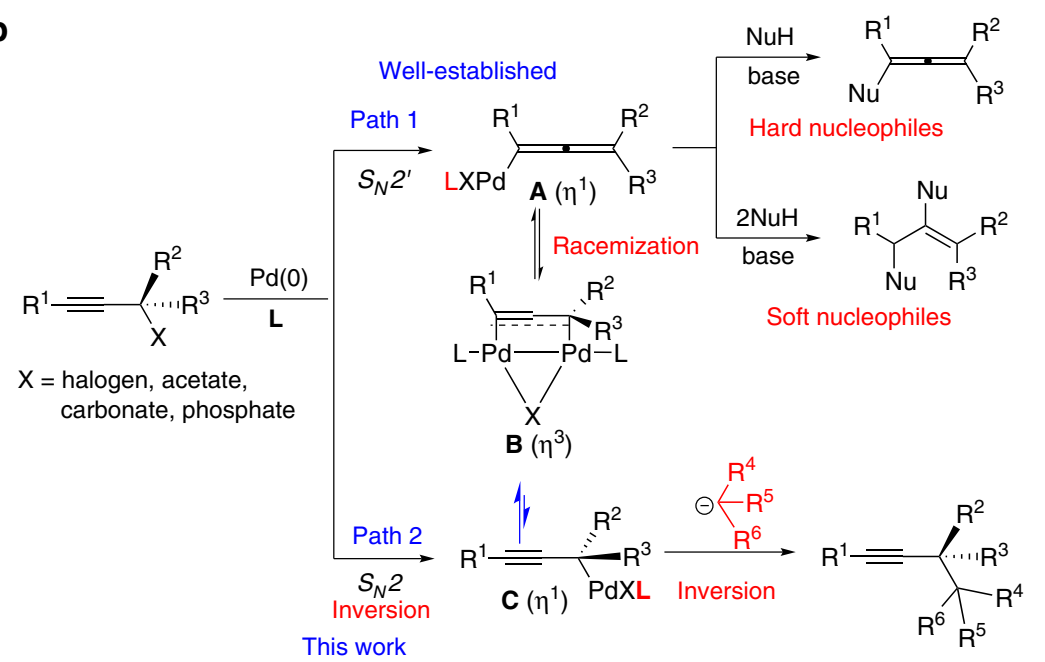

Challenges: (1) No formation of allenyl palladium?

(2) No racemization: double inversion leading to complete configuration retention?

(3) Reactive enough to overcome the steric barrier?

Solution: (1) Ligand effect to form the $\eta^{1}$-propargylic Pd exclusively and keep the Pd in it coordination-saturated, thus, with Pd NOT touching the $\mathrm{C}-\mathrm{C}$ triple bond and avoiding $\beta-\mathrm{H}$ elimination

(2) Propargylic nature of $\mathbf{C}$ for high reactivity

Figure 1 | Formation of vicinal all-carbon quaternary centres. (a) Previous works. (b) This work: new concept for vicinal all-carbon quaternary centres. 
Table 1 | Optimization of reaction conditions ${ }^{\star}$.
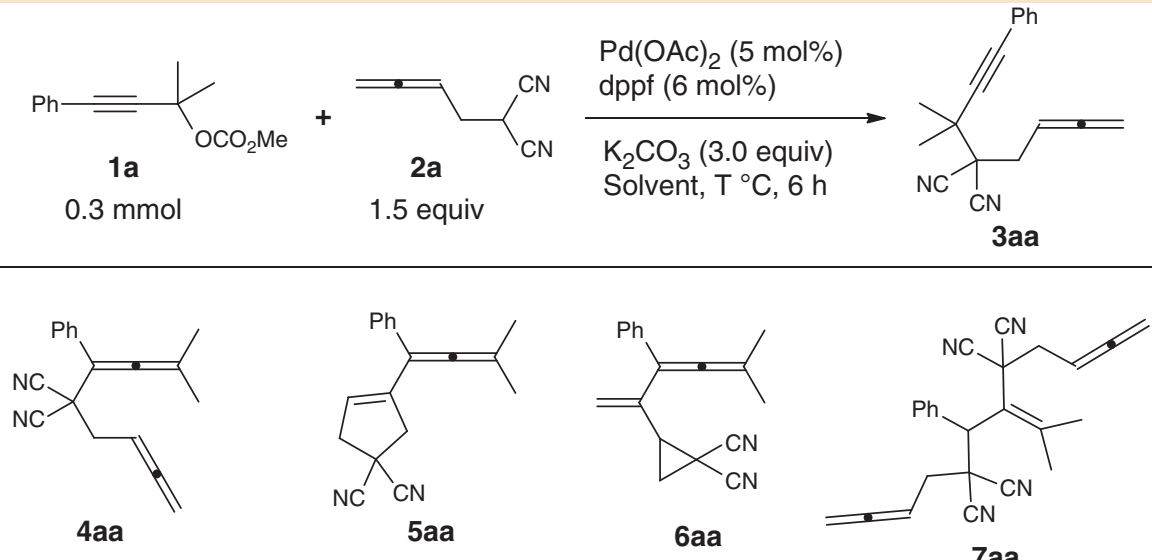

Not observed

\begin{tabular}{|c|c|c|c|c|c|}
\hline Entry & $\mathbf{T}\left({ }^{\circ} \mathrm{C}\right)$ & Solvent & Ligand & Yield of $3 a a(\%)^{\dagger}$ & Recovery of 1a (\%) \\
\hline $1^{\ddagger}$ & 30 & DMSO & dppm & 0 & 69 \\
\hline $2^{\ddagger}$ & 30 & DMSO & dppe & 19 & 60 \\
\hline $3^{\ddagger}$ & 30 & DMSO & dppp & 0 & 88 \\
\hline $4^{\ddagger}$ & 30 & DMSO & $d p p b$ & 5 & 91 \\
\hline $5^{\ddagger}$ & 30 & DMSO & binap & 5 & 75 \\
\hline $6 \pm$ & 30 & DMSO & PPh3 & 0 & 80 \\
\hline $7 \ddagger$ & 30 & DMSO & TFP & 0 & 63 \\
\hline 8 & 30 & DMSO & dppf & $95(94)^{\|}$ & 0 \\
\hline 9 & 50 & DMSO & dppf & 42 & 0 \\
\hline 10 & 70 & DMSO & dppf & 25 & 0 \\
\hline 11 & 30 & THF & dppf & 13 & 79 \\
\hline 12 & 30 & $\mathrm{MeCN}$ & dppf & 26 & 74 \\
\hline 13 & 30 & DMF & dppf & 64 & 26 \\
\hline 14 & 30 & DMA & dppf & 37 & 55 \\
\hline
\end{tabular}

DMA, dimethylacetamide; DMF, dimethylformamide; NMR, nuclear magnetic resonance; TFP, tri(2-furyl)phosphine; THF, tetrahydrofuran

*Reaction conditions: $\mathbf{1 a}(0.3 \mathrm{mmol})$, $\mathbf{2 a}\left(1.5\right.$ equiv.), $\mathrm{Pd}(\mathrm{OAc})_{2}(5 \mathrm{~mol} \%)$, dppf $(6 \mathrm{~mol} \%)$ and $\mathrm{K}_{2} \mathrm{CO}_{3}$ (3.0 equiv.) in solvent $(3.0 \mathrm{ml})$ for $6 \mathrm{~h}$ unless otherwise noted.

$\dagger$ Determined by the ${ }^{1} \mathrm{H}$ NMR analysis of crude product with mesitylene as the internal standard.

tThe reaction time was $24 \mathrm{~h}$.

\$Monophosphine $(12 \mathrm{~mol} \%)$ was used.

|llsolated yield.

compared with the allylic approach shown in equation (3) of Fig. 1a.

In this paper, we wish to report our recent realization of such a concept: the palladium-catalysed reaction of tertiary propargylic carbonates with different fully-loaded carbon nucleophiles to form such carbon-carbon bonds, which nicely remembers the central chirality in the starting propargylic carbonates by applying dppf as the proper ligand.

\section{Results}

Optimization of the reaction. Initially we were studying the coupling cyclization reactions of 2-(2,3-butadienyl)malonitrile 2a with propargylic carbonate 1a for the synthesis of allene compounds 5aa and 6aa (ref. 29). After many trial and error methods with different ligands, Pd catalysts and other reaction parameters, we failed to observe the formation of the expected products 5aa and 6aa from the reaction of methyl (2-methyl-4-phenylbut-3yn-2-yl) carbonate $\mathbf{1 a}(0.3 \mathrm{mmol})$ with 2-(buta-2,3-dien-1yl)malononitrile $2 \mathrm{a}$ (1.5 equiv.) under the catalysis of $\mathrm{Pd}(\mathrm{OAc})_{2}$ $(5 \mathrm{~mol} \%)$ and a ligand $(6 \mathrm{~mol} \%)$ with $\mathrm{K}_{2} \mathrm{CO}_{3}$ (3.0 equiv.) at $30^{\circ} \mathrm{C}$ in dimethylsulphoxide (DMSO) for $6 \mathrm{~h}$ (entries 1-7, Table 1). However, when we used dppe, dppb and BINAP as the ligand, surprisingly, the reaction afforded the targeted propargylic substitution product 3aa in Fig. 1 with two continuous carbon centres, albeit in very low yields, exclusively (entries 2, 4 and 5,
Table 1). Encouraged by this exciting discovery of the formation of two vicinal all-carbon quaternary centres, the influence of the critical reaction parameters was investigated and it was found that 3aa was formed in $94 \%$ isolated yield by running the reaction with dppf, a very bulky ligand (entry 8 , Table 1 )! After screening a series of solvents, DMSO was still proved to be the best: the reactions in tetrahydrofuran, $\mathrm{CH}_{3} \mathrm{CN}$, dimethylformamide or dimethylacetamide all afforded lower yields of 3aa with some recovery of 1a (entries 11-14, Table 1). Thus, the conditions presented in entry 8 of Table 1 have been chosen as the standard for further study.

Substrate scope. With the optimized conditions in hand (entry 8, Table 1), we first examined the reactivity of various tertiary propargylic carbonates $\mathbf{1}$ with 2-(buta-2,3-dien-1-yl)malononitrile $2 \mathrm{a}$. The substrates with the $\mathrm{R}^{1}$ substituent of the alkyne unit being aryl bearing either electron-deficient or electron-rich groups could all proceed smoothly, affording the expected 1,6 -allenyne products in $85-90 \%$ yields (3aa-3da); moreover, the method could be extended to 3-thienyl or $n$-Bu-substituted propargylic carbonates in $84 \%$ yield (3ea, 3fa). In addition, the carbonates where $\mathrm{R}^{2}, \mathrm{R}^{3}$ bore different groups could also be introduced into this transformation in good yields (3ga-3ia). It is worthy of mention that the reaction afforded the corresponding products $3 \mathbf{j a}$ and $\mathbf{3 k a}$ in moderate yields when cyclic tertiary 
Table 2 | The scope of the tertiary propargylic carbonates and tri-substituted carbon nucleophiles ${ }^{\star}$.

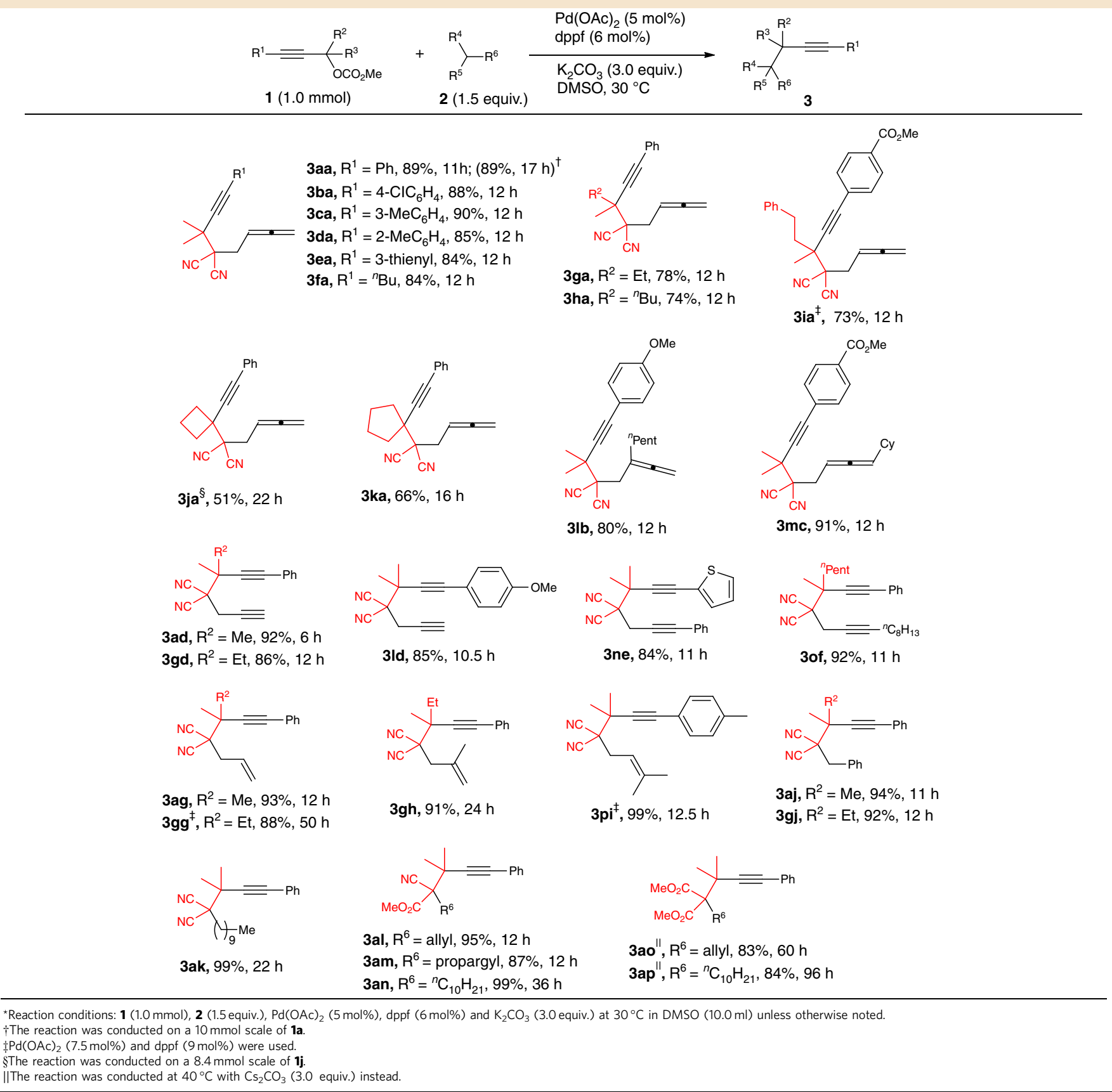

propargylic carbonates $\mathbf{1} \mathbf{j}$ and $\mathbf{1} \mathbf{k}$ (see Supplementary Information for the structures) were applied. The practicality of this reaction has been demonstrated by running the reaction of $\mathbf{1 a}$ on a $10 \mathrm{mmol}$ scale (3aa) and $\mathbf{1} \mathbf{j}$ on an $8.4 \mathrm{mmol}$ scale (3ja). We next explored the scope of functionalized tertiary carbon nucleophiles under optimized conditions. For the 2,3-allenyl malononitriles, we could introduce the $n$-pentyl group at the 2-position (3lb) or the $C y$ group at the 4-position $(3 \mathrm{mc})$; to our delight, different propargylic malononitriles could be applicable to this reaction, affording the 1,6-diyne products in $84-92 \%$ yields (3ad-3of); when various allyl malononitriles were used, the 1,6-enyne products were obtained in excellent yields (3ag-3pi); we also prepared the 1,5-diphenylhexyne derivatives 3aj in 94\% yield and 3gj in $92 \%$ yield with 2-benzylmalononitrile used as the nucleophile. In addition, the method is also proper to a $\mathrm{C}_{10}$-alkyl-substituted malononitrile (3ak). Besides the malononitriles, the tertiary carbon nucleophiles could also be substituted methyl 2-cyanoacetates (3al-3an) and dimethyl malonate (3ao and 3ap).

\section{Discussion}

In order to unveil the mechanism (Fig. 4), the reactions of $(S)$-1g (refs 30,31) (97\% ee), which has a chiral quaternary carbon centre, with different functionalized malononitriles were tried. To our surprise, all the corresponding products, $(S)-3 g a,(S)-3 g d$, $(S)$-3gg and (S)-3gj, were formed with the absolute configuration of the propargylic carbon atom remaining intact and with essentially no loss of enantiomeric purity (Fig. 2).

In order to demonstrate the role of the unique carbon-carbon triple bond, some control experiments were conducted: (1) the reaction of tertiary allylic carbonate $(E)-\mathbf{1 q}$ with 2- 

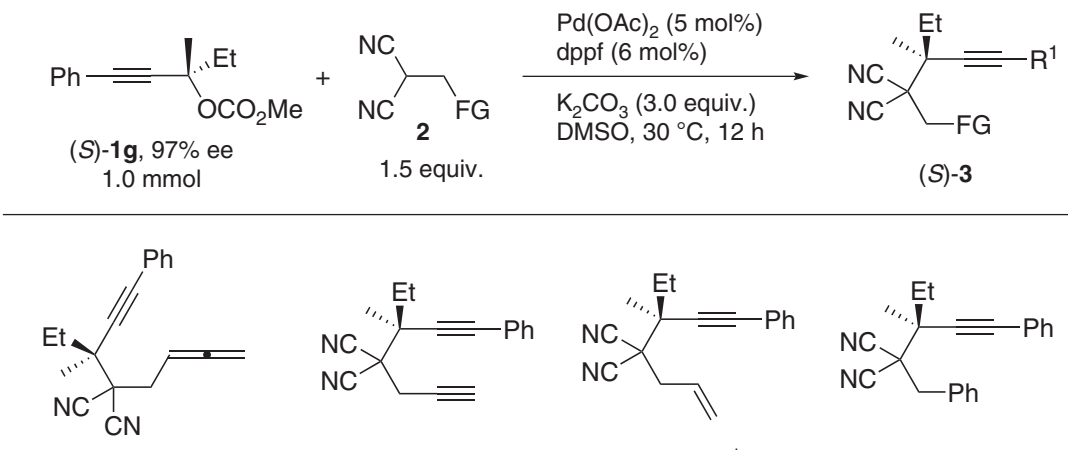

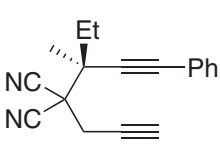

(S)-3gd

(S)-3ga

$79 \%, 97 \%$ ee

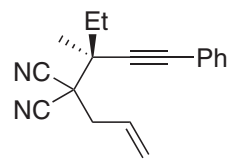

(S) $-\mathbf{3 g g}{ }^{*}$

$87 \%, 97 \%$ ee

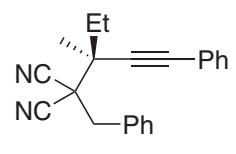

(S) $-3 \mathrm{gj}$

$90 \%, 97 \%$ ee

${ }^{*} \mathrm{Pd}(\mathrm{OAc})_{2}(7.5 \mathrm{~mol} \%)$ and dppf $(9 \mathrm{~mol} \%)$ were used. The reaction time was $60 \mathrm{~h}$.

Figure 2 | Highly entioselective synthesis by chirality transfer. Excellent efficiency of chirality transfer was found when using (S)-19.

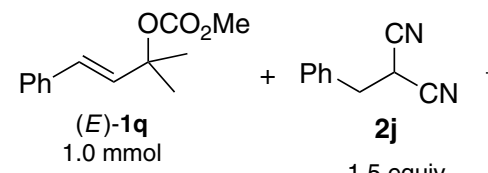

$\mathrm{Pd}(\mathrm{OAc})_{2}(5 \mathrm{~mol} \%)$

dppf $(6 \mathrm{~mol} \%)$

$\mathrm{K}_{2} \mathrm{CO}_{3}$ (3.0 equiv.)

1.5 equiv.

DMSO, $30^{\circ} \mathrm{C}, 36 \mathrm{~h}$<smiles>C=C(C)C=Cc1ccccc1</smiles>

(E)-8, $89 \%$

$92 \%$ recovery by NMR<smiles>C/C(Cl)=C\C(c1ccccc1)C(C)(C#N)Cc1ccccc1</smiles>

9

Not observed 10

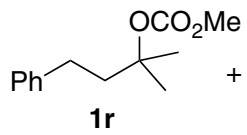

$1.0 \mathrm{mmol}$

$94 \%$ recovery

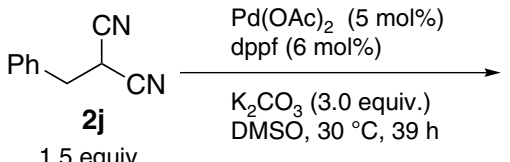

$92 \%$ recovery

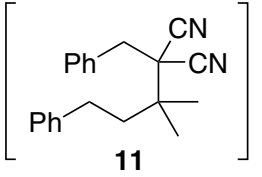

Not observed

Figure 3 | The unique role of the carbon-carbon triple bond. (E)-1q and $\mathbf{1 r}$ failed to afford the corresponding vicinal all-carbon quaternary centres.

benzylmalononitrile $\mathbf{2} \mathbf{j}$ under the standard conditions failed to afford the expected allyl nucleophilic product 9 or 10. Instead, the $\beta$-elimination product, that is, conjugated diene $(E)-\mathbf{8}$, was afforded in $89 \%$ yield. (2) On replacing carbonate $(E)$-1q with saturated tertiary carbonate $1 \mathbf{r}$, no reaction occurred (Fig. 3). Thus, it is concluded that the carbon-carbon triple bond in $\mathbf{1}$ plays a unique role in this nucleophilic substitution reaction.

Based on these results, we propose a possible mechanism, as shown in Fig. 4. The coordination of the $\mathrm{C}-\mathrm{C}$ triple bond in $(S)$-1g with $\mathrm{Pd}(0)$ leads to the formation of coordination complex IN-1. Oxidative addition of the chiral tertiary propargylic carbonate $(S)-1 g$ with $\operatorname{Pd}(0)$ would afford the propargyl $\eta^{1}$-palladium intermediate IN-2 with the first inversion of the absolute configuration of the propargylic carbon atom. Dppf helps to keep this tetra-dentated palladium without forming $\eta^{3}$-dinuclear palladium intermediate IN-3, which avoids any possible racemization through the $\sigma-\pi-\sigma$ isomerization process $^{28}$. Subsequently, the in-situ-generated soft carbon nucleophile would attack this chiral carbon atom from the back side of the C-Pd bond to afford the final nucleophilic substitution product $(S)-3$ with the absolute configuration inverted for the second time and the regeneration of the catalytically active $\operatorname{Pd}(0)$. Overall, the absolute configuration of this propargylic carbon atom remains NOT inverted. Of course, the complete exclusion of allenyl palladium intermediate IN-3 is NOT possible, although such an option may most likely lead to at least partial racemization (see also Fig. 2) 32 $^{32}$

Such propargylation products have been demonstrated to be very useful in synthesis of different molecules with two continuous all-carbon quaternary carbon centres in high efficiency, as shown in Fig. 5: (1) Tricyclic $1 H$-cyclopenta[b]naphthalene derivative $(S) \mathbf{- 1 2}$ was prepared from a tandem reaction of $(S)$-3gd and 1 -iodo-4-nitrobenzene ${ }^{33}$. In fact, the absolute configuration of the chiral propargylation products $(S)$-3ga, (S)-3gd, (S)-3gg and $(S)$-3gj has been established on the basis of an X-ray single-crystal diffraction study of this product. (2) The 1,6-allenyne derivative $\mathbf{3 j a}$ and $(S)$-3 ga could go through a thermal $[2+2]$ reaction $^{34,35}$ to construct the tricyclic product 13ja containing two highly strained four-membered rings and bicyclic product (S)-13ga containing one highly strained four-membered ring in very high yields. (3) In addition, the hydrogenation or semi-hydrogenation of the carbon-carbon triple bond in $(S)$-3gj afforded saturated (S)-14 under $15 \mathrm{~mol} \%$ of $\mathrm{Pd} / \mathrm{C}$ catalyst or $(S, Z)-15$ with a $Z$-double bond under $10 \mathrm{~mol} \%$ of the Lindlar catalyst, respectively ${ }^{36,37}$.

In conclusion, we have developed a new concept of a palladium-catalysed propargylation of functionalized 
tri-substituted carbon nucleophiles with tertiary propargylic carbonates, which provides a very practical and useful method to construct a $\mathrm{C}-\mathrm{C}$ bond between two tert-carbon atoms forming different 1,6-allenyne, 1,6-diyne, 1,6-enyne and 1,6-arenyne derivatives, which are important types of versatile compounds in organic chemistry-related disciplines. Moreover, no racemization occurred to the central chirality in the tertiary propargylic

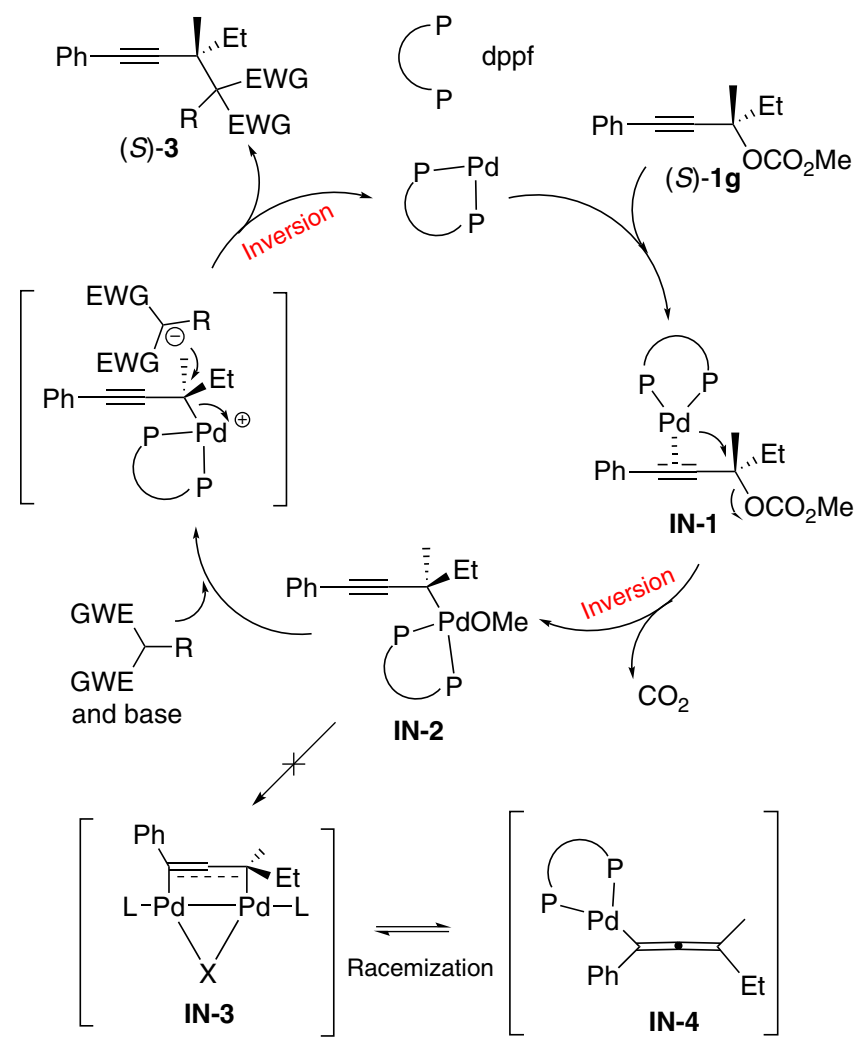

Figure 4 | A plausible mechanism. Dppf helps to keep the tetra-dentated palladium coordination saturated avoiding racemization. carbonates, which makes enantioselective synthesis of such molecules possible. Due to the presence of the triple bond and the demonstrated scope of the substrates, this reaction expands the scope of the existing methodologies for the construction of two vicinal all-carbon quaternary centres. Further studies on expanding the scope of the reaction, the mechanism, synthetic applications and development of enantioselective version of this reaction are being actively pursued in our laboratory.

\section{Methods}

Materials. DMSO was stirred with $\mathrm{CaH}_{2}$ for $12 \mathrm{~h}$ at $80^{\circ} \mathrm{C}$ and distilled in vacuo before use. $\mathrm{Pd}(\mathrm{OAc})_{2}$ was purchased from Acros. Dppf was purchased from Energy Chemical. $\mathrm{K}_{2} \mathrm{CO}_{3}$ was purchased from Sinopharm Chemical Reagent Co., Ltd. $\mathrm{Pd} / \mathrm{C}$ was purchased from Alfa Aesar. Lindlar catalyst was purchased from J\&K. Other commercially available chemicals were purchased and used without additional purification unless noted otherwise.

General spectroscopic methods. ${ }^{1} \mathrm{H}$ nuclear magnetic resonance (NMR) spectra were recorded on a Bruker- $300 \mathrm{MHz}$ spectrometer and ${ }^{13} \mathrm{C}$ NMR spectra were recorded at $75 \mathrm{MHz}$. All ${ }^{1} \mathrm{H}$ NMR experiments were measured with tetramethylsilane (0 p.p.m.) or the signal of residual $\mathrm{CHCl}_{3}$ (7.26 p.p.m.) in $\mathrm{CDCl}_{3}$ as the internal reference; ${ }^{13} \mathrm{C}$ NMR experiments were measured relative to the signal of $\mathrm{CDCl}_{3}$ (77.0 p.p.m.). Infrared spectra were recorded from films of pure samples on sodium chloride plates for liquid samples or in the form of $\mathrm{KBr}$ discs for solid samples. Mass and HRMS spectra were carried out in EI mode. Elemental analysis was carried out by Elementar Vario MICRO cube. Thin-layer chromatography was performed on pre-coated glass-back plates and visualized with UV light at $254 \mathrm{~nm}$. Flash column chromatography was performed on silica gel. ${ }^{1} \mathrm{H}$ NMR, ${ }^{13} \mathrm{C}$ NMR and HPLC spectra (for chiral compounds) are supplied for all compounds (see Supplementary Figs 1-137). See Supplementary Methods for the characterization data of compounds not listed in this part.

Synthesis of 3aa. To a flame-dried Schlenk tube containing $\mathrm{K}_{2} \mathrm{CO}_{3}(414.2 \mathrm{mg}$, $3.0 \mathrm{mmol})$ were added $\mathrm{Pd}(\mathrm{OAc})_{2}(11.4 \mathrm{mg}, 0.05 \mathrm{mmol})$, dppf $(33.4 \mathrm{mg}, 0.06 \mathrm{mmol})$, 1a $(217.5 \mathrm{mg}, 1.0 \mathrm{mmol}) / \mathrm{DMSO}(8.0 \mathrm{ml})$ and $2 \mathrm{a}(178.0 \mathrm{mg}, 1.5 \mathrm{mmol}) / \mathrm{DMSO}$ $(2.0 \mathrm{ml})$ sequentially under nitrogen atmosphere. The reaction was complete after being stirred at $30^{\circ} \mathrm{C}$ for $11 \mathrm{~h}$ as monitored by TLC (eluent: petroleum ether/ethyl acetate $=20 / 1)$. After cooling to room temperature $(\mathrm{rt})$, the resulting mixture was quenched with an aqueous solution of diluted hydrochloric acid $(v / v=10 \%$, prepared via diluting commercially available concentrated hydrochloric acid with water according to the volume ratio; $10 \mathrm{ml}$ ) slowly and extracted with ethyl ether $(30 \mathrm{ml} \times 3)$. The combined organic layer was washed with water and brine, and dried over anhydrous $\mathrm{Na}_{2} \mathrm{SO}_{4}$. After filtration and evaporation of the solvent, chromatography on silica gel (eluent: petroleum ether/ethyl acetate $=20 / 1$ ) afforded 3aa (226.4 mg, 89\%) as a liquid: ${ }^{1} \mathrm{H}$ NMR (300 MHz, $\left.\mathrm{CDCl}_{3}\right) \delta 7.46-7.38$
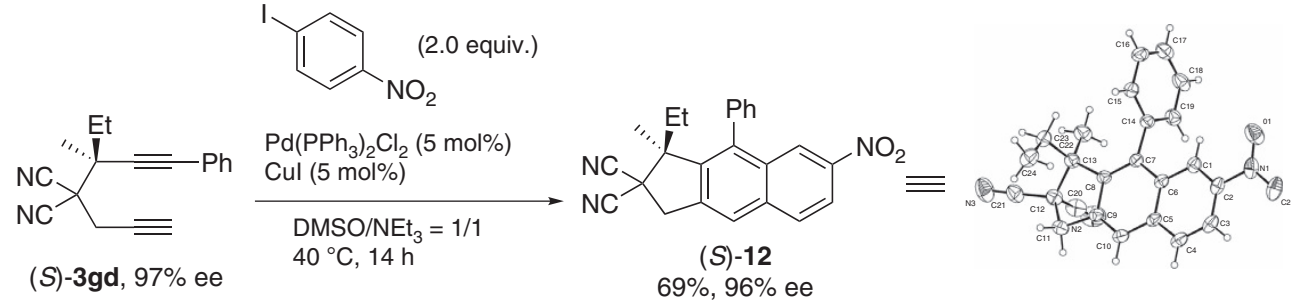

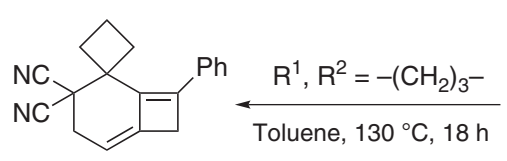

13ja, $82 \%$<smiles>[R7]C(C#CPc1ccccc1)C(C#N)(C#N)CC=C=C</smiles>

3ja or (S)-3ga, 97\% ee

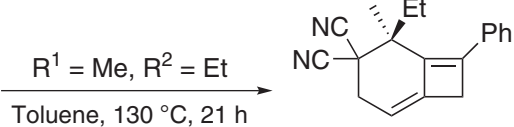

(S)-13ga

$91 \%, 97 \%$ ee<smiles>CC[C@@](C)(CCc1ccccc1)C(C#N)(C#N)Cc1ccccc1</smiles>

(S) -14

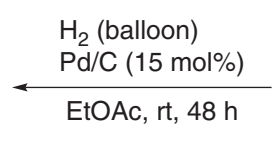

EtOAc, rt, $48 \mathrm{~h}$

$92 \%, 96 \%$

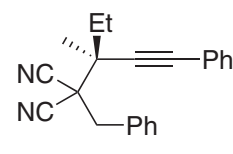

(S)-3gj, 97\% ee

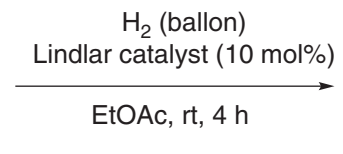

EtOAc, rt, $4 \mathrm{~h}$<smiles>CC[C@@](C)(/C=C\c1ccccc1)C(C#N)(C#N)Cc1ccccc1</smiles>

(S,Z)-15

$89 \%, 97 \%$ ee

Figure $\mathbf{5}$ | The synthetic applications. Several molecules with two continuous all-carbon quaternary carbons centres were afforded. 
(m, 2H, ArH), 7.36-7.25 (m, 3H, ArH), 5.40-5.28 (m, 1H, CH=), 4.95 $\left(\mathrm{dt}, J_{1}=6.7 \mathrm{~Hz}, J_{2}=2.4 \mathrm{~Hz}, 2 \mathrm{H},=\mathrm{CH}_{2}\right), 2.82\left(\mathrm{dt}, J_{1}=7.6 \mathrm{~Hz}, J_{2}=2.3 \mathrm{~Hz}, 2 \mathrm{H}\right.$, $\left.\mathrm{CH}_{2}\right), 1.63(\mathrm{~s}, 6 \mathrm{H}, \mathrm{Me} \times 2) ;{ }^{13} \mathrm{C} \mathrm{NMR}\left(75 \mathrm{MHz}, \mathrm{CDCl}_{3}\right) \delta 210.5,131.6,128.7$, $128.2,121.5,113.9,87.9,85.9,83.0,77.1,48.7,39.4,33.7,25.7$; IR (neat, $\mathrm{cm}^{-1}$ ) $3,063,2,985,2,942,2,869,2,245,2,221,1,956,1,598,1,491,1,470,1,459,1,443$, $1,393,1,373,1,291,1,252,1,161,1,091,1,071,1,028$; MS (EI): $m / z(\%) 260$ $\left(\mathrm{M}^{+}, 100\right)$; HRMS calcd. for $\mathrm{C}_{18} \mathrm{H}_{16} \mathrm{~N}_{2}\left(\mathrm{M}^{+}\right)$: 260.1313 ; found: 260.1310 .

Synthesis of (S)-3ga. Following the procedure for the synthesis of 3aa, the reaction of $\mathrm{K}_{2} \mathrm{CO}_{3}(413.7 \mathrm{mg}, 3.0 \mathrm{mmol}), \mathrm{Pd}(\mathrm{OAc})_{2}(11.4 \mathrm{mg}, 0.05 \mathrm{mmol})$, dppf (33.3 mg, $0.06 \mathrm{mmol}),(S)-1 \mathrm{~g}(97 \%$ ee, $233.2 \mathrm{mg}, 1.0 \mathrm{mmol}) / \mathrm{DMSO}(8.0 \mathrm{ml})$ and $2 \mathrm{a}$ $(177.5 \mathrm{mg}, 1.5 \mathrm{mmol}) / \mathrm{DMSO}(2.0 \mathrm{ml})$ at $30^{\circ} \mathrm{C}$ for $12 \mathrm{~h}$ afforded $(S)-3 \mathrm{ga}(217.5 \mathrm{mg}$, $79 \%$ ) as a liquid (eluent: petroleum ether/ethyl acetate $=20 / 1$ ): $97 \%$ ee (HPLC conditions: Chiralcel IC column, hexane $/ i-\mathrm{PrOH}=200 / 1,0.6 \mathrm{ml} / \mathrm{min}, \lambda=214 \mathrm{~nm}$, $t_{\mathrm{R}}($ major $\left.)=35.3 \mathrm{~min}, t_{\mathrm{R}}(\operatorname{minor})=37.8 \mathrm{~min}\right) ;[\alpha]_{\mathrm{D}}^{20}=+32.2\left(c=1.055, \mathrm{CHCl}_{3}\right)$; ${ }^{1} \mathrm{H}$ NMR $\left(300 \mathrm{MHz}, \mathrm{CDCl}_{3}\right) \delta 7.49-7.39(\mathrm{~m}, 2 \mathrm{H}, \mathrm{ArH}), 7.38-7.26(\mathrm{~m}, 3 \mathrm{H}, \mathrm{ArH})$, $5.41-5.28(\mathrm{~m}, 1 \mathrm{H},=\mathrm{CH}), 4.95\left(\mathrm{dt}, J_{1}=6.5 \mathrm{~Hz}, J_{2}=2.3 \mathrm{~Hz}, 2 \mathrm{H},=\mathrm{CH}_{2}\right), 2.94-2.75$ $\left(\mathrm{m}, 2 \mathrm{H}, \mathrm{CH}_{2}\right), 2.11-1.95\left(\mathrm{~m}, 1 \mathrm{H}\right.$, one proton of $\left.\mathrm{CH}_{2}\right), 1.86-1.71(\mathrm{~m}, 1 \mathrm{H}$, one proton of $\left.\mathrm{CH}_{2}\right), 1.56(\mathrm{~s}, 3 \mathrm{H}, \mathrm{Me}), 1.21(\mathrm{t}, J=7.4 \mathrm{~Hz}, 3 \mathrm{H}, \mathrm{Me}) ;{ }^{13} \mathrm{C} \mathrm{NMR}(75 \mathrm{MHz}$ $\left.\mathrm{CDCl}_{3}\right) \delta 210.7,131.7,128.8,128.3,121.7,114.1,87.3,86.7,83.1,77.1,49.3,44.1$, 33.7, 30.7, 21.7, 9.5; IR (neat, $\mathrm{cm}^{-1}$ ) 3,062, 2,978, 2,941, 2,883, 2,247, 2,228, 1,956, $1,598,1,491,1,461,1,443,1,386,1,321,1,250,1,131,1,091,1,070 ;$ MS (EI): $m / z(\%)$ $274\left(\mathrm{M}^{+}, 100\right)$; HRMS calcd. for $\mathrm{C}_{19} \mathrm{H}_{18} \mathrm{~N}_{2}\left(\mathrm{M}^{+}\right)$: 274.1470; Found: 274.1469.

Synthesis of (S)-12. To a flame-dried Schlenk tube were added $\mathrm{Pd}\left(\mathrm{PPh}_{3}\right)_{2} \mathrm{Cl}_{2}$ (17.6 mg, $0.025 \mathrm{mmol}), \mathrm{CuI}(4.9 \mathrm{mg}, 0.025 \mathrm{mmol}), 1$-iodo-4-nitrobenzene (249.3 mg, $1.0 \mathrm{mmol}),(S)-3$ gd $(97 \%$ ee, $130.2 \mathrm{mg}, 0.5 \mathrm{mmol}) / \mathrm{DMSO}(2.0 \mathrm{ml})$ and $\mathrm{NEt}_{3}(2.0 \mathrm{ml})$ sequentially under nitrogen atmosphere. The reaction was complete after being stirred at $40^{\circ} \mathrm{C}$ for $14 \mathrm{~h}$ as monitored by TLC (eluent: petroleum ether/ethyl acetate $=10 / 1)$. After cooling to rt, the resulting mixture was diluted with ethyl acetate $(30 \mathrm{ml})$ and washed with water $(20 \mathrm{ml})$. The organic layer was separated and the aqueous layer was extracted with ethyl acetate $(20 \mathrm{ml})$. The combined organic layer was washed with brine and dried over anhydrous $\mathrm{Na}_{2} \mathrm{SO}_{4}$. After filtration and evaporation, the residue was purified by chromatography (eluent: petroleum ether/ethyl acetate/dichloromethane $=10 / 1 / 1$ ) on silica gel to afford (S)-12 (129.5 mg, 69\%) as a solid: $96 \%$ ee (HPLC conditions: Chiralcel OD-H column, hexane $/ i-\mathrm{PrOH}=80 / 20,1.0 \mathrm{ml} \mathrm{min}^{-1}, \lambda=214 \mathrm{~nm}, t_{\mathrm{R}}($ major $)=9.5 \mathrm{~min}$, $t_{\mathrm{R}}($ minor $\left.)=10.3 \mathrm{~min}\right) ;[\alpha]_{\mathrm{D}}^{20}=-33.9\left(c=0.975, \mathrm{CHCl}_{3}\right) ;$ m.p. $205-206^{\circ} \mathrm{C}$ $\left(n\right.$-hexane/DCM); ${ }^{1} \mathrm{H}$ NMR $\left(300 \mathrm{MHz}, \mathrm{CDCl}_{3}\right) \delta 8.26-8.18(\mathrm{~m}, 2 \mathrm{H}, \mathrm{ArH})$, 8.00-7.93 (m, 1H, ArH), 7.90 (s, 1H, ArH), 7.62-7.49 (m, 3H, ArH), 7.34-7.22 $(\mathrm{m}, 2 \mathrm{H}, \mathrm{ArH}), 3.93\left(\mathrm{dd}, J_{1}=16.4 \mathrm{~Hz}, J_{2}=1.1 \mathrm{~Hz}, 1 \mathrm{H}\right.$, one proton of $\left.\mathrm{CH}_{2}\right), 3.84$ (dd, $J_{1}=16.5 \mathrm{~Hz}, J_{2}=1.2 \mathrm{~Hz}, 1 \mathrm{H}$, one proton of $\left.\mathrm{CH}_{2}\right), 1.95-1.78(\mathrm{~m}, 1 \mathrm{H}$, one proton of $\left.\mathrm{CH}_{2}\right), 1.58-1.39\left(\mathrm{~m}, 1 \mathrm{H}\right.$, one proton of $\left.\mathrm{CH}_{2}\right), 1.42(\mathrm{~s}, 3 \mathrm{H}, \mathrm{Me}), 0.98$ $(\mathrm{t}, J=7.5 \mathrm{~Hz}, 3 \mathrm{H}, \mathrm{Me}) ;{ }^{13} \mathrm{C} \mathrm{NMR}\left(75 \mathrm{MHz}, \mathrm{CDCl}_{3}\right) \delta 145.7,141.9,139.2,138.0$, $135.4,135.3,133.1,130.4,130.1,129.1,128.9,128.50,128.46,123.7,123.1,119.9$, $115.3,114.8,57.3,44.8,41.6,32.3,22.9,9.2$; IR $\left(\mathrm{KBr}, \mathrm{cm}^{-1}\right) 3,078,3,057,2,978$, $2,931,2,883,2,249,1,628,1,610,1,584,1,531,1,490,1,460,1,442,1,391,1,377$, $1,339,1,287,1,266,1,218,1,090,1,054,1,028$; MS (EI): $m / z(\%) 381\left(\mathrm{M}^{+}, 51.55\right)$, 352 (100); anal. calcd. for $\mathrm{C}_{24} \mathrm{H}_{19} \mathrm{~N}_{3} \mathrm{O}_{2}$ (\%): C 75.57, $\mathrm{H}$ 5.02, N 11.02; found: C 75.60, H 5.05, N 11.19.

Synthesis of 13ja. To a flame-dried Schlenk tube was added $3 \mathbf{j a}(273.2 \mathrm{mg}$, $1.0 \mathrm{mmol}) /$ toluene $(10 \mathrm{ml})$ under nitrogen atmosphere. The reaction was complete after being stirred at $130^{\circ} \mathrm{C}$ for $18 \mathrm{~h}$ as monitored by TLC (eluent: petroleum ether/ ethyl acetate $=20 / 1$ ). After cooling to $\mathrm{rt}$ and evaporation of the solvent, the residue was purified by chromatography (eluent: petroleum ether/ethyl acetate/ dichloromethane $=20 / 1 / 1)$ on silica gel to afford $13 \mathbf{j a}(223.1 \mathrm{mg}, 82 \%)$ as a solid: m.p. $133-135^{\circ} \mathrm{C}\left(n\right.$-hexane/DCM); ${ }^{1} \mathrm{H}$ NMR $\left(300 \mathrm{MHz}, \mathrm{CDCl}_{3}\right) \delta 7.54-7.29$ $(\mathrm{m}, 5 \mathrm{H}, \mathrm{ArH}), 5.17(\mathrm{t}, J=3.9 \mathrm{~Hz}, 1 \mathrm{H},=\mathrm{CH}), 3.32\left(\mathrm{~s}, 2 \mathrm{H}, \mathrm{CH}_{2}\right), 2.86(\mathrm{~d}, J=3.9 \mathrm{~Hz}$, $\left.2 \mathrm{H}, \mathrm{CH}_{2}\right), 2.80-2.43\left(\mathrm{~m}, 4 \mathrm{H}, \mathrm{CH}_{2} \times 2\right), 2.40-2.21\left(\mathrm{~m}, 2 \mathrm{H}, \mathrm{CH}_{2}\right) ;{ }^{13} \mathrm{C} \mathrm{NMR}$ $\left(75 \mathrm{MHz}, \mathrm{CDCl}_{3}\right) \delta 142.1,139.1,138.5,133.4,128.7,128.6,127.2,115.2,102.0,44.6$, 42.4, 35.9, 31.9, 28.6, 14.0; IR (KBr, cm $\left.{ }^{-1}\right)$ 3,056, 2,991, 2,941, 2,914, 2,247, 1,754, $1,595,1,490,1,445,1,435,1,353,1,321,1,246,1,180,1,157,1,097,1,033$; MS (EI): $m / z(\%) 272\left(\mathrm{M}^{+}, 39.83\right), 244(100)$; anal. calcd. for $\mathrm{C}_{19} \mathrm{H}_{16} \mathrm{~N}_{2}(\%)$ : C 83.79, H 5.92, N 10.29; found: C 83.58, H 5.85, N 10.25 .

Synthesis of 14. To a dry Schlenk tube were added Pd/C (dry, $w / w(\mathrm{Pd})=10 \%$, $32.2 \mathrm{mg}, 0.03 \mathrm{mmol})$ and $\mathbf{3 g j}(63.0 \mathrm{mg}, 0.2 \mathrm{mmol}) /$ EtOAc $(4 \mathrm{ml})$ sequentially. The resulting mixture was frozen with a liquid nitrogen bath, degassed and refilled with $\mathrm{H}_{2}$ for three times. Then the reaction was allowed to stir at rt with a $\mathrm{H}_{2}$ balloon. After $48 \mathrm{~h}$, the reaction was completed as monitored by TLC (petroleum ether/ethyl acetate $=20 / 1)$. The mixture was filtrated through a short column of silica gel with EtOAc $(20 \mathrm{ml} \times 3)$. After evaporation, the residue was purified by chromatography (eluent: petroleum ether/ethyl acetate $=15 / 1$ ) on silica gel to afford 14 (57.1 mg, 89\%) as a solid: m.p. $112-113{ }^{\circ} \mathrm{C}$ (hexane/DCM); ${ }^{1} \mathrm{H}$ NMR $\left(300 \mathrm{MHz}, \mathrm{CDCl}_{3}\right): \delta 7.50-7.15(\mathrm{~m}, 10 \mathrm{H}, \mathrm{ArH}), 3.13\left(\mathrm{~s}, 2 \mathrm{H}, \mathrm{CH}_{2}\right), 2.86-2.64$ $\left(\mathrm{m}, 2 \mathrm{H}, \mathrm{CH}_{2}\right), 2.12-1.70\left(\mathrm{~m}, 4 \mathrm{H}, \mathrm{CH}_{2} \times 2\right), 1.34(\mathrm{~s}, 3 \mathrm{H}, \mathrm{Me}), 1.14(\mathrm{t}, J=7.4 \mathrm{~Hz}, 3 \mathrm{H}$ $\mathrm{Me}) ;{ }^{13} \mathrm{C} \mathrm{NMR}\left(75 \mathrm{MHz}, \mathrm{CDCl}_{3}\right) \delta 141.2,132.7,130.5,128.7,128.63,128.58,128.2$, 126.3, 115.0, 49.7, 43.5, 38.4, 38.0, 30.8, 29.0, 21.5, 9.0; IR (KBr, $\left.\mathrm{cm}^{-1}\right)$ 3,087, 3,066,
$3,024,2,975,2,949,2,881,2,239,1,599,1,498,1,472,1,455,1,435,1,386,1,239$, 1,090, 1,031, 1,010; MS (EI): $m / z(\%) 316\left(\mathrm{M}^{+}, 2.17\right), 91$ (100); anal. calcd. for $\mathrm{C}_{22} \mathrm{H}_{24} \mathrm{~N}_{2}$ (\%): C 83.50, H 7.64, N 8.85; found: C 83.41, H 7.72, N 8.75.

Synthesis of $(S, Z)-15$. Following procedure for the synthesis of 14 , the reaction of lindlar catalyst (palladium on calcium carbonate, $w / w(\mathrm{Pd})=5 \%$, poisoned with lead acetate, $42.5 \mathrm{mg}, 0.02 \mathrm{mmol}),(S)-3 \mathrm{gj}(62.0 \mathrm{mg}$. $0.2 \mathrm{mmol})$ and $\mathrm{H}_{2}$ in EtOAc $(4.0 \mathrm{ml})$ at $\mathrm{rt}$ for $4 \mathrm{~h}$ afforded $(S, Z)-\mathbf{1 5}(55.7 \mathrm{mg}, 89 \%)$ as a solid (eluent: petroleum ether/ethyl acetate $=30 / 1$ ): $97 \%$ ee (high-performance liquid chromatography (HPLC) conditions: Chiralcel AD-H column, hexane/ $i-\mathrm{PrOH}=200 / 1$, $0.6 \mathrm{ml} \mathrm{min}^{-1}, \lambda=214 \mathrm{~nm}, t_{\mathrm{R}}($ minor $)=35.5 \mathrm{~min}, t_{\mathrm{R}}($ major $\left.)=41.2 \mathrm{~min}\right)$ $[\alpha]_{\mathrm{D}}^{20}=+142.7\left(c=0.96, \mathrm{CHCl}_{3}\right) ;$ m.p. $112-113^{\circ} \mathrm{C}$ (hexane/dichloromethane (DCM)); ${ }^{1} \mathrm{H}$ NMR $\left(300 \mathrm{MHz}, \mathrm{CDCl}_{3}\right): \delta 7.47-7.23$ (m, 8H, ArH), 7.22-7.14 (m, 2H, $\mathrm{ArH}), 7.09(\mathrm{~d}, J=12.9 \mathrm{~Hz}, 1 \mathrm{H}, \mathrm{CH}=), 5.62(\mathrm{~d}, J=12.9 \mathrm{~Hz}, 1 \mathrm{H}, \mathrm{CH}=), 3.22$ $\left(\mathrm{d}, J=13.2 \mathrm{~Hz}, 1 \mathrm{H}\right.$, one proton of $\left.\mathrm{CH}_{2}\right), 3.11\left(\mathrm{~d}, J=13.2 \mathrm{~Hz}, 1 \mathrm{H}\right.$, one proton of $\left.\mathrm{CH}_{2}\right)$, 2.04-1.88 (m, $1 \mathrm{H}$, one proton of $\left.\mathrm{CH}_{2}\right), 1.81-1.67\left(\mathrm{~m}, 1 \mathrm{H}\right.$, one proton of $\left.\mathrm{CH}_{2}\right), 1.02$ $(\mathrm{t}, J=7.4 \mathrm{~Hz}, 3 \mathrm{H}, \mathrm{Me}), 0.98(\mathrm{~s}, 3 \mathrm{H}, \mathrm{Me}) ;{ }^{13} \mathrm{C} \mathrm{NMR}\left(75 \mathrm{MHz} \mathrm{CDCl}_{3}\right) \delta 137.4,135.9$ $132.8,130.4,130.1,128.8,128.5,128.0,127.8,127.1,114.60,114.56,51.1,49.4,38.8$, $31.8,18.8,9.0$; IR (KBr, cm ${ }^{-1}$ ) 3,062, 3,033, 2,974, 2,941, 2,881, 2,242, 1,599, 1,492, 1,456, 1,442, 1,388, 1,124, 1,090, 1,071, 1,025; MS (EI): $m / z(\%) 314\left(\mathrm{M}^{+}, 0.13\right), 159$ (100); anal. calcd. for $\mathrm{C}_{22} \mathrm{H}_{22} \mathrm{~N}_{2}$ (\%): C 84.04, H 7.05, N 8.91; found: C 83.95, H 7.11, N 8.78.

Data availability. The authors declare that all the data supporting the findings of this study are available within the article and its Supplementary Information files.

\section{References}

1. Steven, A. \& Overman, L. E. Total synthesis of complex cyclotryptamine alkaloids: stereocontrolled construction of quaternary carbon stereocenters. Angew. Chem. Int. Ed. 46, 5488-5508 (2007).

2. Shimizu, Y., Shi, S., Usuda, H., Kanai, M. \& Shibasaki, M. Catalytic asymmetric total synthesis of ent-Hyperforin. Angew. Chem. Int. Ed. 49, 1103-1106 (2010).

3. Corey, E. J. \& Lin, S. A short enantioselective total synthesis of Dammarenediol II. J. Am. Chem. Soc. 118, 8765-8766 (1996).

4. Bhat, V., Allan, K. M. \& Rawal, V. H. Total synthesis of $N$-methylwelwitindolinone D isonitrile. J. Am. Chem. Soc. 133, 5798-5801 (2011).

5. Trost, B. M. \& Jiang, C. Catalytic enantioselective construction of all-carbon quaternary stereocenters. Synthesis 369-396 (2006).

6. Peterson, E. A. \& Overman, L. E. Contiguous stereogenic quaternary carbons a daunting challenge in natural products synthesis. Proc. Natl Acad. Sci. USA 101, 11943-11948 (2004).

7. Wang, B. \& Tu, Y. Q. Stereoselective construction of quaternary carbon stereocenters via a semipinacol rearrangement strategy. Acc. Chem. Res. 44, 1207-1222 (2011).

8. Gao, L., Hwang, G.-S. \& Ryu, D. H. Oxazaborolidinium ion-catalyzed cyclopropanation of $\alpha$-substituted acroleins: enantioselective synthesis of cyclopropanes bearing two chiral quaternary centers. J. Am. Chem. Soc. 133, 20708-20711 (2011)

9. Zhang, H., Hong, L., Kang, H. \& Wang, R. Construction of vicinal all-carbon quaternary stereocenters by catalytic asymmetric alkylation reaction of 3-bromooxindoles with 3-substituted indoles: total synthesis of (+)-perophoramidine. J. Am. Chem. Soc. 135, 14098-14101 (2013).

10. Ohmatsu, K., Ando, Y. \& Ooi, T. Asymmetric substitution at the tetrasubstituted chiral carbon: catalytic ring-opening alkylation of racemic 2,2-disubstituted aziridines with 3-substituted oxindoles. J. Am. Chem. Soc. 135, 18706-18709 (2013).

11. Lee, C. W., Han, S.-J., Virgil, S. C. \& Stoltz, B. M. Stereochemical evaluation of bis(phosphine) copper catalysts for the asymmetric alkylation of 3-bromooxindoles with a-arylated malonate esters. Tetrahedron 71, 3666-3670 (2015).

12. Trost, B. M., Cramer, N. \& Silverman, S. M. Enantioselective construction of spirocyclic oxindolic cyclopentanes by palladium-catalyzed trimethylenemethane[3+2]-cycloaddition. J. Am. Chem. Soc. 129, 12396-12397 (2007).

13. Evans, P. A., Kennedy, L. J., Evans, P. A. \& Kennedy, L. J. Regioselective rhodium-catalyzed allylic alkylation/ring-closingmetathesis approach to carbocycles. Tetrahedron Lett. 42, 7015-7018 (2001).

14. Plietker, B. A highly regioselective salt-free iron-catalyzed allylic alkylation. Angew. Chem. Int. Ed. 45, 1469-1473 (2006).

15. Dieskau, A. P., Holzwarth, M. S. \& Plietker, B. Fe-catalyzed multicomponent reactions: the regioselective alkoxy allylation of activated olefins and its application in sequential Fe catalysis. Chem. Eur. J. 18, 2423-2429 (2012)

16. Trost, B. M., Malhotra, S. \& Chan, W. H. Exercising regiocontrol in palladiumcatalyzed asymmetric prenylations and geranylation: unifying strategy toward flustramines A and B. J. Am. Chem. Soc. 133, 7328-7331 (2011).

17. Ruchti, J. \& Carreira, E. M. Ir-catalyzed reverse prenylation of 3-substituted indoles: total synthesis of $(+)$-aszonalenin and $(-)$-brevicompanine B. J. Am. Chem. Soc. 136, 16756-16759 (2014) 
18. Ohmatsu, K., Imagawa, N. \& Ooi, T. Ligand-enabled multiple absolute stereocontrol in metal-catalysed cycloaddition for construction of contiguous all-carbon quaternary stereocentres. Nat. Chem. 6, 49-51 (2014).

19. Kawatsura, M., Sato, M., Tsuji, H., Ata, A. \& Itoh, T. Retention of regiochemistry and chirality in the ruthenium catalyzed allylic alkylation of disubstituted allylic esters. J. Org. Chem. 76, 5485-5488 (2011).

20. Tsuji, J., Watanabe, H., Minami, I. \& Shimizu, I. Novel palladium-catalyzed reactions of propargyl carbonates with carbonucleophiles under neutral conditions. J. Am. Chem. Soc. 107, 2196-2198 (1985).

21. Tsuji, J. \& Mandai, T. Palladium-catalyzed reactions of propargylic compounds in organic synthesis. Angew. Chem. Int. Ed. Engl. 34, 2589-2612 (1995).

22. Guo, L., Duan, X. \& Liang, Y. Palladium-catalyzed cyclization of propargylic compounds. Acc. Chem. Res. 44, 111-122 (2011).

23. Ma, S. \& Wang, G. Regioselectivity control by a ligand switch in the coupling reaction involving allenic/propargylic palladium species. Angew. Chem. Int. Ed. Engl. 42, 4215-4217 (2003).

24. Yoshida, M., Higuchi, M. \& Shishido, K. Highly diastereoselective synthesis of tetrahydrobenzofuranones by palladium-catalyzed reaction of propargylic carbonates with 2-substituted cyclohexane-1,3-diones. Tetrahedron Lett. 49, 1678-1681 (2008).

25. Yoshida, M., Higuchi, M. \& Shishido, K. Highly diastereoselective synthesis of tetrahydrobenzofuran derivatives by palladium-catalyzed reaction of propargylic esters with substituted $\beta$-dicarbonyl compounds. Tetrahedron 66, 2675-2682 (2010).

26. Ambrogio, I., Cacchi, S., Fabrizi, G., Goggiamani, A. \& Iazzetti, A. Palladium-catalyzed nucleophilic substitution of propargylic carbonates and Meldrum's acid derivatives. Eur. J. Org. Chem. 2015, 3147-3151 (2015).

27. Ardolino, M. J. \& Morken, J. P. Construction of 1,5-enynes by stereospecific Pd-catalyzed allyl - propargyl cross-couplings. J. Am. Chem. Soc. 134, 8770-8773 (2012).

28. Ogoshi, S., Nishida, T., Shinagawa, T. \& Kurosawa, H. Key process in palladium-catalyzed asymmetric transformation of propargyl electrophiles. Racemization of optically active $\eta^{1}$-allenylpalladium(II). J. Am. Chem. Soc. 123, 7164-7165 (2001)

29. Ye, J. \& Ma, S. Palladium-catalyzed cyclization reactions of allenes in the presence of unsaturated carbon - carbon bonds. Acc. Chem. Res. 47, 989-1000 (2014).

30. Forrat, V. J., Prieto, O., Ramón, D. J. \& Yus, M. trans-1-Sulfonylamino-2isoborneolsulfonylaminocyclohexane derivatives: excellent chiral ligands for the catalytic enantioselective addition of organozinc reagents to ketones. Chem. Eur. J. 12, 4431-4445 (2006).

31. Wu, S. et al. A C-H bond activation-based catalytic approach to tetrasubstituted chiral allenes. Nat. Commun. 6, 7946 (2015).

32. Marshall, J. A. \& Wolf, M. A. Amination, aminocarbonylation, and alkoxycarbonylation of allenic/propargylic Pd intermediates derived from nonracemic propargylic mesylates: synthesis of nonracemic propargyl amines, allenic amides, and butenolides. J. Org. Chem. 61, 3238-3239 (1996).

33. Zhu, S., Cao, J., Wu, L. \& Huang, X. Synthesis of polycyclic isoindoline derivatives via tandem Pd-catalyzed coupling, propargyl-allenyl isomerization, $[4+2]$ cycloaddition and aromatization reaction. J. Org. Chem. 77, 10409-10415 (2012).
34. Ohno, H., Mizutani, T., Kadoh, Y., Miyamura, K. \& Tanaka, T. Thermal intramolecular [2+2] cycloaddition of allenenes and allenynes: diastereoselective access to bicyclic nitrogen heterocycles. Angew. Chem. Int Ed. 44, 5113-5115 (2005).

35. Mailyan, A. K., Krylov, I. M., Bruneau, C., Dixneuf, P. H. \& Osipov, S. N. Thermal $[2+2]$ cycloaddition of CF3-substituted allenynes: access to novel cyclobutene-containing $\alpha$-amino acids. Synlett 2321-2324 (2011).

36. Huang, X., Jiang, X., Fu, C. \& Ma, S. Palladium(0)-catalyzed regioselective synthesis of macrocycles from allenes with a nucleophilic functionality and organic iodides. Adv. Synth. Catal. 355, 3295-3303 (2013).

37. Demel, P., Keller, M. \& Breit, B. $o$-DPPB-directed copper-mediated and -catalyzed allylic substitution with Grignard reagents. Chem. Eur. J. 12, 6669-6683 (2006).

\section{Acknowledgements}

Financial support from the National Natural Basic Research Program of China (2015CB856600) and National Natural Science Foundation of China (21232006) is greatly appreciated. We thank Mr Zheng Yang in this group for reproducing the preparation of 3ba, 3al and (S)-3gd. S.M. is a Qiu Shi Adjunct Professor at Zhejiang University.

\section{Author contributions}

S.M. directed the research and developed the concept of the reaction with X.H. X.H., S.W. and W.W. performed the experiments and data analysis. P.L. prepared some tertiary propargylic carbonates. X.H., C.F. and S.M. checked all the data analysis. The paper was written by X.H. and S.M. with assistance from the other authors.

\section{Additional information}

Supplementary Information accompanies this paper at http://www.nature.com/ naturecommunications

Competing financial interests: The authors declare no competing financial interests.

Reprints and permission information is available online at http://npg.nature.com/ reprintsandpermissions/

How to cite this article: Huang, X. et al. Palladium-catalysed formation of vicinal all-carbon quaternary centres via propargylation. Nat. Commun. 7:12382 doi: $10.1038 /$ ncomms12382 (2016).

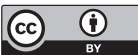

This work is licensed under a Creative Commons Attribution 4.0 International License. The images or other third party material in this article are included in the article's Creative Commons license, unless indicated otherwise in the credit line; if the material is not included under the Creative Commons license, users will need to obtain permission from the license holder to reproduce the material. To view a copy of this license, visit http://creativecommons.org/licenses/by/4.0/

(C) The Author(s) 2016 